\title{
Polyunsaturated fatty acids in treatment of acute remitting multiple sclerosis
}

\author{
D BATES, P R W FAWCETT, D A SHAW, D WEIGHTMAN
}

British Medical fournal, 1978, 2, 1390-1391

\section{Summary and conclusions}

One hundred and sixteen patients with acute remitting multiple sclerosis (MS) took part in a double-blind controlled trial of treatment with polyunsaturated fatty acids and were randomly allocated to one of four groups. Two groups received linoleic acid, one alone as a spread and one with $\gamma$-linolenic acid in capsules (Naudicelle); and two control groups received oleic acid, one as a spread and one in capsules. Rates of clinical deterioration and frequencies of attacks were not significantly different between treated and control groups. Exacerbations were shorter and less severe in patients receiving a high dose of linoleic acid than in controls, but those receiving a lower dose-that is, Naudicelle-showed no such difference.

Thus supplementing the diet with $20 \mathrm{~g}$ linoleic acid marginally affected the duration and severity of relapses of MS but had no effect on overall disability. The dose of Naudicelle used provided insufficient supplementation.

\section{Introduction}

An association between multiple sclerosis (MS) and dietary fats was suggested after epidemiological data related disease prevalence to diet in different populations. ${ }^{1-4}$. Biochemical studies showed a specific deficiency of linoleic acid in the serum of patients with MS. ${ }^{5}$ Results of a trial of linoleic acid in these patients ${ }^{6}$ suggested that relapses were less frequent, less severe, and of shorter duration than those in controls. The rate of clinical deterioration was not affected.

In the present study one group of patients received linoleic acid and another oleic acid, the doses being similar to those used in the study of Millar et al. ${ }^{6}$ The suggestion that linoleic acid combined with $\gamma$-linolenic acid might be more effective than linoleic acid alone- $\gamma$-linolenic acid is incorporated into structural brain lipids more readily ${ }^{7}$ and possibly has a greater effect on immune function ${ }^{8}$-led to the inclusion of a cohort of patients who received such a mixture (Naudicelle) in capsule form and who were matched by a control group taking identical capsules containing oleic acid. The trial included patients with chronic progressive and acute remitting disease. The results in those with chronic progressive disease have been reported ${ }^{9}$; we now present the results in the patients with acute remitting MS.

Department of Neurology, Royal Victoria Infirmary, Newcastle upon Tyne NE1 4LP

D BATES, MB, MRCP, senior lecturer

P R W FAWCETT, MB, MRCP, senior registrar (present address: Regional Neurological Centre, Newcastle General Hospital, Newcastle upon Tyne NE4 6BE)

D A SHAW, MB, FRCP, professor

Department of Medical Statistics, University of Newcastle upon Tyne, Newcastle upon Tyne NE1 7RU

D WEIGHTMAN, assistant

\section{Patients and methods}

We admitted 116 patients to the trial and randomly allocated them to one of four groups. Group A received eight capsules daily of Naudicelle oil, totalling $2.92 \mathrm{~g}$ of linoleic acid and $0.34 \mathrm{~g}$ of $\gamma$-linolenic $\vec{\circ}$ acid; group $B$ took eight similar capsules, providing $4 \mathrm{~g}$ of oleic acid daily; group C received $23 \mathrm{~g}$ of linoleic acid daily in a spread; and $\vec{\omega}$ group D received $16 \mathrm{~g}$ of oleic acid daily in a spread. Thus groups $A$ and $C$ received "active" treatment and groups $B$ and $D$ served as controls. Dosages of fatty acids in groups $\mathrm{C}$ and $\mathrm{D}$ were similar to those given by Millar et $a l,{ }^{6}$ though the vehicle was different.

Neurological and functional assessments were performed at sixweekly intervals during the two years of the study. Overall disability $\overrightarrow{0}$ was scored on the Kurtzke Disability Status Scale. ${ }^{10}$ Separate assessments of pyramidal, cerebellar, brain stem, sensory, sphincter, visual, and mental functions were summed to form the "objective assessment."

Relapses were recorded, noting duration, site, and severity. The severity of the relapse was scored by the method of Millar et al. ${ }^{11}$ At entry to the trial and between 12 and 24 months later fasting blood $Z$ samples were taken from randomly selected patients for estimations of fatty acids. All patients underwent liver function tests and routine blood counts at intervals to identify possible toxic effects, and histocompatibility antigens were determined to establish the evenness of distribution between the groups.

\section{Results}

Table I gives details of the patients who took part in the trial. The ages and durations of history of patients in the four groups were not significantly different. There was no significant difference in the distribution of histocompatibility antigens between the groups. The overall tendency for an increase in histocompatibility antigens A3 and B7 in patients with MS compared with local controls was confirmed. ${ }^{12}$

TABLE I-Compositions of the four groups at start of trial, and numbers of patients defaulting and dying within the two years

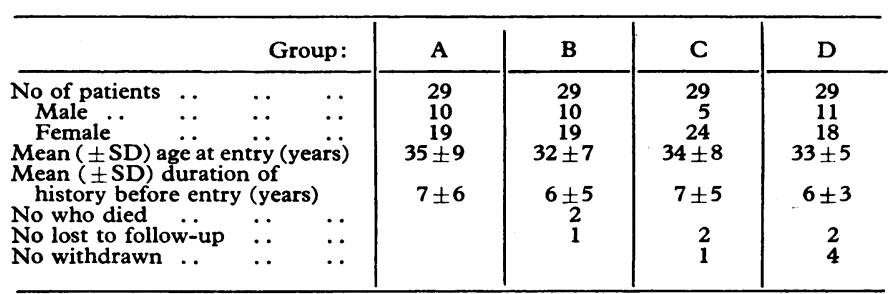

Results were evaluated in terms of clinical deterioration and frequency and severity of attacks. Clinical deterioration was determined by the score on the Kurtzke Disability Status Scale and the objective assessment. The only significant finding related to group A (receiving Naudicelle), as after two years significantly more patients had deteriorated than had improved, which did not occur in any other group. Also after two years the number of patients who had deteriorated in group $\mathbf{A}$ was significantly greater than that in group $\mathbf{B}$ (control capsules) $(\mathbf{P}<0.05)$. There was a suggestion after other intervals that patients receiving Naudicelle fared worse than patients in the other groups, but the differences were not significant. The same results emerged when objective assessment was compared between the groups.

The frequency of attacks was not significantly different between the four groups (table II). More patients receiving the control capsules tended to be free of attacks, and group B as a whole had fewer attacks per patient-year than the other groups, but the differences were not significant. The mean duration of exacerbations in each patient was 
TABLE II-Number of attacks in each group during two years of trial

\begin{tabular}{|c|c|c|c|c|}
\hline Group: & A & B & $\mathrm{C}^{\circ}$ & D \\
\hline $\begin{array}{l}\text { Patients having no attacks } \\
\text { Patients with } 1-2 \text { attacks } \\
\text { Patients with } 3 \text { or more attacks }\end{array}$ & $\begin{array}{r}4 \\
6 \\
19\end{array}$ & $\begin{array}{r}7 \\
11\end{array}$ & $\begin{array}{r}3 \\
12 \\
14\end{array}$ & $\begin{array}{r}4 \\
7 \\
17\end{array}$ \\
\hline $\begin{array}{l}\text { Total number of attacks } \\
\text { Attacks per patient-year* }\end{array}$ & $\begin{array}{c}105 \\
1 \cdot 2\end{array}$ & $\begin{array}{l}66 \\
0 \cdot 8\end{array}$ & $\begin{array}{l}86 \\
1 \cdot 0\end{array}$ & $\begin{array}{l}89 \\
1 \cdot 2\end{array}$ \\
\hline
\end{tabular}

*Patients defaulting before two years were included for their appropriate patientyears.

compared between the four groups. Patients in group C (linoleic acid spread) had attacks of significantly shorter duration than those in group D (control spread). When the "attack score," measuring severity and duration of attacks and expressed in terms of mean score per attack per patient, was compared between the groups a significant difference in favour of group $\mathrm{C}$ as against group $\mathrm{D}$ was again evident (Mann-Whitney U test in both cases).

Estimations of total fatty acids in patients before and after 12-24 months' treatment showed that the percentage of linoleic and arachidonic acids increased significantly only in those patients taking the linoleic acid spread (group C). Patients receiving Naudicelle tended to show a similar but smaller increase in concentrations of polyunsaturated fatty acids (PUFA), and control patients tended to show increased monounsaturated fatty acid concentrations, but neither change was significant.

\section{Discussion}

The evidence supporting an abnormality of fatty acid metabolism in MS is substantial. ${ }^{13}$ Whatever the cause of the abnormality, an empirical attempt to improve the dietary supply of linoleic acid by supplementation with sunflower oil produced results that were encouraging but inconclusive. ${ }^{6}$ In a trial in patients with chronic progressive MS we failed to show any significant benefit in those receiving a dietary supplement of linoleic acid alone or combined with $\gamma$-linolenic acid. ${ }^{9}$ In the present trial we repeated the study of Millar et al. ${ }^{6}$ We used a spread provided by Unilever rather than a pure oil in view of the known unpleasantness of the oil. Our study also incorporated a group receiving Naudicelle.

We were unable to show any difference in long-term effects between those patients receiving PUFA supplementation and controls. We doubt that the apparent difference in the numbers deteriorating in groups $A$ and $B$ truly reflects an adverse effect of Naudicelle. Our patients receiving the active preparations did not have any fewer attacks. The only patients who did benefit from dietary supplementation were those in group C, whose attacks were shorter and less severe. They received $23 \mathrm{~g}$ of linoleic acid daily and therefore closely resembled the patients in the series of Millar et al. ${ }^{6}$

Analysis of the serum fatty acids confirmed that the dietary supplement in group $C$ increased the percentage of PUFA in serum. In contrast, patients in group $A$, who did not benefit clinically, showed no significant increase in percentages of PUFA while receiving Naudicelle. Presumably this was because the dosage of linoleic acid in the Naudicelle capsule is so much lower than that in the spread. The $\gamma$-linolenic acid in the capsules does not appear to have increased significantly the serum concentrations of the long-chain PUFA.

The way in which PUFA produce their clinical effect is unknown, but since adequate dietary supplementation with linoleic acid appears to influence only the duration and severity of acute exacerbations it would seem to resemble adrenocorticotrophic hormone in its action. ${ }^{14}$ This would accord with the suggested immunosuppressive function of PUFA, and since serum lipid concentrations can be fairly rapidly altered by dietary supplementation, high doses of PUFA could perhaps be used as acute treatment during an exacerbation of MS. Recent evidence suggests that PUFA protect guinea pigs from experimental allergic encephalomyelitis. ${ }^{15}$ This may be either due to incorporation of PUFA into lymphocyte membrane or because PUFA are prostaglandin precursors, which, especially those of the $\mathrm{E}$ series, act as immunosuppressants in vivo and in vitro. ${ }^{16}$ In studies of experimental allergic encephalomyelitis Mertin ${ }^{15}$ used large amounts of PUFA as a dietary supplement. He originally gave diets containing $2000 \mathrm{mg} / \mathrm{kg}$ of linoleic acid or $\gamma$-linolenic acid per day, but then reduced this to $500 \mathrm{mg} / \mathrm{kg}$ daily and still found a protective effect. If species differences are ignored, the lower dose may be compared with the $250 \mathrm{mg} / \mathrm{kg}$ daily given by Millar et $a l^{6}$ and the $350 \mathrm{mg} / \mathrm{kg}$ daily given to patients in our group C. By comparison, the patients in group $\mathbf{A}$ received only $50 \mathrm{mg} / \mathrm{kg}$ of PUFA per day. Thus the dose of Naudicelle used in this trial, even allowing for the possible increased biological activity of $\gamma$-linolenic acid, is much lower than the amounts used by Mertin ${ }^{15}$ and Millar et $a l^{6}$ and in our own group C.

We have thus confirmed that it is possible, by supplementing the diet with linoleic acid, to increase the percentage of PUFA in serum lipids in patients with MS. While this supplementation had no effect on overall disability, it marginally affected the duration and severity of relapses. Present evidence suggests that $20 \mathrm{~g}$ of linoleic acid per day provides adequate supplementation, but futher studies may show that smaller doses have the same effects on serum fatty acids. We believe that the dose of Naudicelle used in our trial was inadequate. To have achieved the necessary increase in blood concentrations patients would have had to swallow 40 capsules per day.

We are indebted to the Multiple Sclerosis Society of Great Britain and Northern Ireland for financing the trial, including the purchase of Naudicelle capsules. We thank Van den Berghs Limited for supplying gratis the spreads containing linoleic acid and oleic acid. Dr S Murray and Mr P Dewar of the Regional Blood Transfusion Service kindly undertook histocompatibility antigen determinations. Professor F Gunstone, of the department of chemistry, St Andrews University, was responsible for the analyses of serum fatty acids. Finally, we are indebted to neurological colleagues who referred patients to us.

Details of estimations of fatty acids and statistical analyses may be obtained from the authors by request.

\section{References}

${ }^{1}$ Swank, R L, American fournal of the Medical Sciences, 1950, 220, 421

2 Swank, R L, et al, New England fournal of Medicine, 1952, 246, 721.

3 Swank, R L, Archives of Neurology and Psychiatry, 1953, 69, 91.

4 Sinclair, H M, Lancet, 1956, 1, 381 .

5 Thompson, R H S, Proceedings of the Royal Society of Medicine, 1966, 59, 269.

${ }^{6}$ Millar, J H D, et al, British Medical fournal, 1973, 1, 765.

7 Mead, J F, and Howton, D R, fournal of Biological Chemistry, 1957, 229, 575.

${ }^{8}$ Field, E J, and Shenton, B K, Acta Neurologica Scandinavica, 1975, 52, 121.

9 Bates, D, et al, British Medical fournal, 1977, 2, 932.

10 Kurtzke, J F, Neurology, 1961, 11, 686.

11 Millar, J H D, et al, Lancet, 1967, 2, 429.

12 Batchelor, J R, British Medical Bulletin, 1977, 33, 72

13 Mertin, J, and Meade, C J, British Medical Bulletin, 1977, 33, 67.

14 Miller, H G, et al, British Medical fournal, 1962, 1, 1726.

15 Mertin, J, personal communication.

${ }_{16}$ Pelus, L M, and Strausser, H R, Life Sciences, 1977, 20, 903.

(Accepted 26 September 1978) 